\title{
Multiple organ failure of tumor-bearing rabbits in cancer cachexia is caused by apoptosis of normal organ cells
}

\author{
TAKESHI FUKUDA, TOSHIYUKI SUMI, HIROYUKI NOBEYAMA, HIROYUKI YOSHIDA, \\ YOSHINARI MATSUMOTO, TOMOYO YASUI, KEN-ICHI HONDA and OSAMU ISHIKO \\ Department of Obstetrics and Gynecology, Osaka City University Graduate \\ School of Medicine, 1-4-3, Asahimachi, Abeno-ku, Osaka 545-8585, Japan
}

Received August 18, 2008; Accepted October 17, 2008

DOI: 10.3892/ijo_00000129

\begin{abstract}
In cancer-bearing animals, we previously demonstrated that skeletal muscle apoptosis may be involved in muscle wasting and that Bax may play a role in skeletal muscle cell apoptosis at an early stage. In this study, we investigated the occurrence of apoptosis in the liver, kidney, spleen, lung and heart during cancer cachexia as well as the associations between apoptosis and the expression levels of $\mathrm{Bcl}-2, \mathrm{Bcl}-\mathrm{x}_{\mathrm{L}}$ and Bax proteins. We also examined the relationship between normal organ apoptosis in cancer cachexia and multiple organ failure. We further studied the changes in body weight, lean body mass (LBM), apoptotic index (AI), DNA laddering pattern and expression levels of $\mathrm{Bax}, \mathrm{Bcl}-2$ and $\mathrm{Bcl}-\mathrm{x}_{\mathrm{L}}$ in the liver, kidney, spleen, lung and heart in VX2 carcinoma-bearing rabbits. In the early stage of tumor bearing (20 days after implantation), the LBM was significantly reduced by $19.06 \pm 1.02 \%$ in the tumor-bearing group compared to an increase of $1.66 \pm 0.83 \%$ in the control group. The apoptotic indices of the liver, kidney, lung and spleen in the tumor-bearing group increased by $14.2 \pm 1.8 \%$, $34.4 \pm 2.0 \%, 66.7 \pm 6.0 \%$ and $24.8 \pm 3.8 \%$, respectively and were significantly higher than the corresponding indices in the control group. DNA laddering patterns characteristic of DNA fragmentation were visible on day 50 in the liver, kidney, spleen and lung in the tumor-bearing group. The expression of Bax increased in the tumor-bearing group and coincided with the occurrence of apoptosis. However, no significant changes were noted in the expression levels of Bcl-2 and Bcl- $\mathrm{x}_{\mathrm{L}}$. These findings suggest the possibility that normal organ cell apoptosis related to Bax not only causes body weight loss but also multiple organ failure in cancer cachexia.
\end{abstract}

Correspondence to: Dr Toshiyuki Sumi, Department of Obstetrics and Gynecology, Osaka City University Graduate School of Medicine, 1-4-3, Asahimachi, Abeno-ku, Osaka 545-8585, Japan E-mail: sumi-toshi@med.osaka-cu.ac.jp

Key words: apoptosis, cancer cachexia, multiple organ failure, Bax, $\mathrm{Bcl}-2, \mathrm{Bcl}-\mathrm{x}_{\mathrm{L}}$

\section{Introduction}

Cachexia is probably the most common complication in cancer patients (1). Anorexia, anemia, immunodeficiency, body weight loss and alterations in carbohydrate, lipid and protein metabolism can occur early in the course of cancer cachexia. Although the etiology of cancer cachexia remains unclear, it appears to be associated with metabolic competition, malnutrition or circulating humoral factors (2). Therefore, cancer-bearing individuals can have multiple organ failure and are prone to death.

Apoptosis plays key roles in various biological processes and functions and occurs in many different tumor and normal tissues. Various proteins related to apoptosis have already been identified, and two of them, Bcl-2 and $\mathrm{Bcl}-\mathrm{x}_{\mathrm{L}}$, are known to suppress apoptosis. By contrast, another member of the Bcl-2 family, Bax, promotes apoptosis (3-5).

We previously demonstrated apoptosis of normal muscle cells and normal adipocytes as well as the presence of Bax in these cells in tumor-bearing rabbits at an early stage $(6,7)$. These findings suggested that skeletal muscle and adipose tissue wasting in the early stage may be caused by a different mechanism from that in the late stage. The aim of this study was to investigate both the occurrence of normal organ cell apoptosis during cancer cachexia and the associations between apoptosis and the expression levels of Bcl-2, Bcl- $\mathrm{x}_{\mathrm{L}}$ and $\mathrm{Bax}$ proteins. Moreover, we examined the possibility that normal organ cell apoptosis is the cause of multiple organ failure.

\section{Materials and methods}

Experimental animals. Twenty male Japanese white rabbits weighing $3 \mathrm{~kg}$ (SCC Co., Shizuoka, Japan) were divided into two groups, i.e., a tumor-bearing group $(n=15)$ and a control group $(n=5)$. The right thigh muscles of the animals in the tumor-bearing group were implanted with $1 \times 10^{5} \mathrm{VX} 2$ carcinoma cells in $1 \mathrm{ml}$ of $0.15 \mathrm{M} \mathrm{NaCl}$ (8), while the right thigh muscles of the control group were injected with $1 \mathrm{ml}$ of $0.15 \mathrm{M} \mathrm{NaCl}$. The animals were housed under constant temperature and humidity conditions and given access to water and food. The control animals were provided with the same amount of food as the tumor-bearing group. Body weight and lean body mass (LBM) were measured every 10 days after tumor implantation. 
After general anesthesia with intravenous pentobarbital sodium $(25 \mathrm{mg} / \mathrm{kg}$ ), sets of 4 animals (3 tumor-bearing animals and 1 control animal) were sacrificed on days 20, 30, 40, 50 and 60 after VX2 tumor implantation, and their livers, spleens, kidneys, lungs and hearts resected. Specimens from these organs were fixed in $10 \%$ neutral-buffered formalin to prepare paraffin sections.

Measurement of body composition. Following the intravenous injection of pentobarbital sodium, total body electrical conductivity (TOBEC) values were measured using a TOBEC small animal body composition analysis system (inner diameter, 203 mm; length, 617 mm; Model SA3203; EMSCAN Inc., Springfield, IL). The measurements were made by observing the changes in impedance in the measurement chamber when the animal was exposed to a $10-\mathrm{MHz}$ magnetic field. The LBM was calculated from the TOBEC value using the following formula (9): $\mathrm{LBM}=1.536 \mathrm{x}$ TOBEC value +475.1 .

In situ detection of apoptosis. Apoptosis in organ tissues was evaluated by terminal deoxynucleotidyl transferase-mediated dUTP-biotin nick end-labeling (TUNEL) (10) using an in situ apoptosis detection kit (Takara, Otsu, Japan) according to the manufacturer's instructions. The apoptotic index (AI), defined as the ratio of TUNEL-positive cells viewed in the observation field of a x200 objective lens relative to the total cell number, values were used for analysis and compared among the different animal groups. Two different people blinded to the animal treatments counted the positive cells in three microscopic fields on one slide from each specimen and their counts did not differ significantly.

DNA laddering patterns. Tissues collected from each rabbit were cut into very fine pieces, homogenized in phosphatebuffered saline (PBS) and subjected to DNA extraction using an apoptotic DNA ladder extraction kit (MBL, Nagoya, Japan) according to the manufacturer's instructions. The extracts were electrophoresed in $1.2 \%$ agarose gels, stained with ethidium bromide, visualized by transillumination with UV light and photographed.

Immunohistochemistry. The expression levels of Bax, Bcl-2 and $\mathrm{Bcl}-\mathrm{x}_{\mathrm{L}}$ were investigated in paraffin-embedded sections by the avidin-biotin-peroxidase complex method. Paraffinembedded sections (5- $\mu \mathrm{m}$ thick) were deparaffinized and immersed in $3 \%$ hydrogen peroxidase to block endogenous peroxidase activity. Next, the sections were subjected to an antigen retrieval procedure by immersion in $10 \mathrm{mM}$ citrate buffer ( $\mathrm{pH}$ 6.0) and heating in an autoclave at $121^{\circ} \mathrm{C}$ for $15 \mathrm{~min}$. After washing in PBS, the tissue sections were preblocked with $10 \%$ normal goat serum for $15 \mathrm{~min}$ and stained according to the protocol of an LSAB 2 peroxidase kit (Dako, Kyoto, Japan). Briefly, the sections were incubated overnight with appropriate primary antibodies in a humidity chamber at $4^{\circ} \mathrm{C}$. The primary antibodies used in this study were mouse anti-human Bax (Santa Cruz Biotechnology, Santa Cruz, CA), Bcl-2 (Nichirei, Tokyo, Japan) and Bcl- $\mathrm{x}_{\mathrm{L}}$ (Santa Cruz Biotechnology) monoclonal antibodies. The working dilutions of the primary antibodies

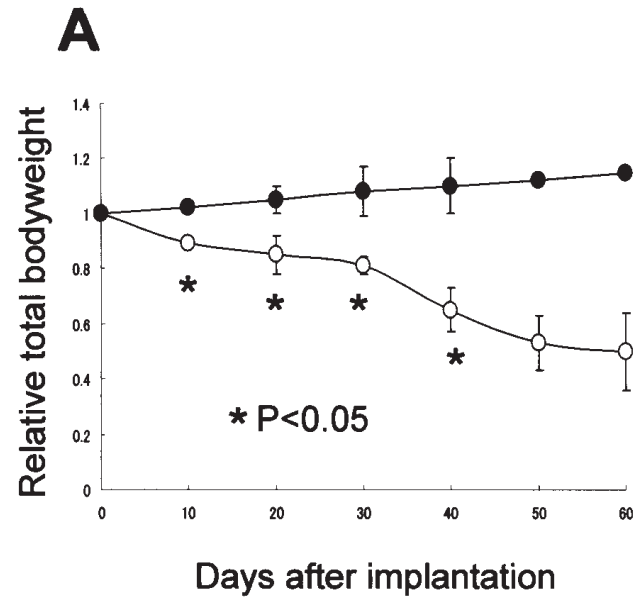

B

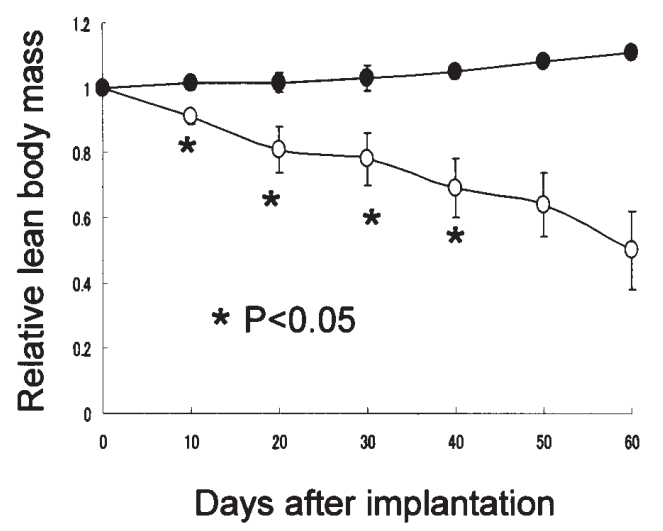

Figure 1. Total body weight (A) and lean body mass (B) of tumor-bearing and control rabbits. Open circles, tumor-bearing rabbits; closed circles, control rabbits. Values are mean \pm SD expressed as ratios according to the values on day $0 .{ }^{*} \mathrm{P}<0.05$ vs. the control group (Student's t-test).

were 1:25 for anti-Bax, no dilution for anti-Bcl-2 and 1:25 for anti-Bcl- $\mathrm{X}_{\mathrm{L}}$. The sections were rinsed with PBS for $15 \mathrm{~min}$ and incubated with the secondary antibodies (biotinylated goat anti-mouse and -rabbit immunoglobulin $\mathrm{G}$ secondary antibody; Dako) for $1 \mathrm{~h}$. The sections were then incubated with streptavidin-peroxidase complexes and color was developed using 3,3'-diamino-benzidine as the chromogen. The sections were counterstained with Mayer's hematoxylin. The specificity of the immunohistochemical reactions was checked by omitting the primary antibody.

Quantitative analyses of the Bax, Bcl-2 and Bcl- $\mathrm{x}_{\mathrm{L}}$ expression levels were based on a previously reported scoring method (11). The mean percentages of positively stained tumor cells were determined in five areas using a x400 magnification objective and the specimens were classified according to the following categories: $0,<5 \% ; 1,5-25 \% ; 2$, $25-50 \% ; 3,50-75 \%$ and $4,>75 \%$. The immunostaining intensity was scored as follows: $1+$, weak; $2+$, moderate; $3+$, intense. For each specimen, the percentage of positively stained tumor cells was multiplied by the staining intensity to produce a weighted score.

Statistical analysis. Student's t-test and the Mann-Whitney U test were used to analyze the data for significant differences. 

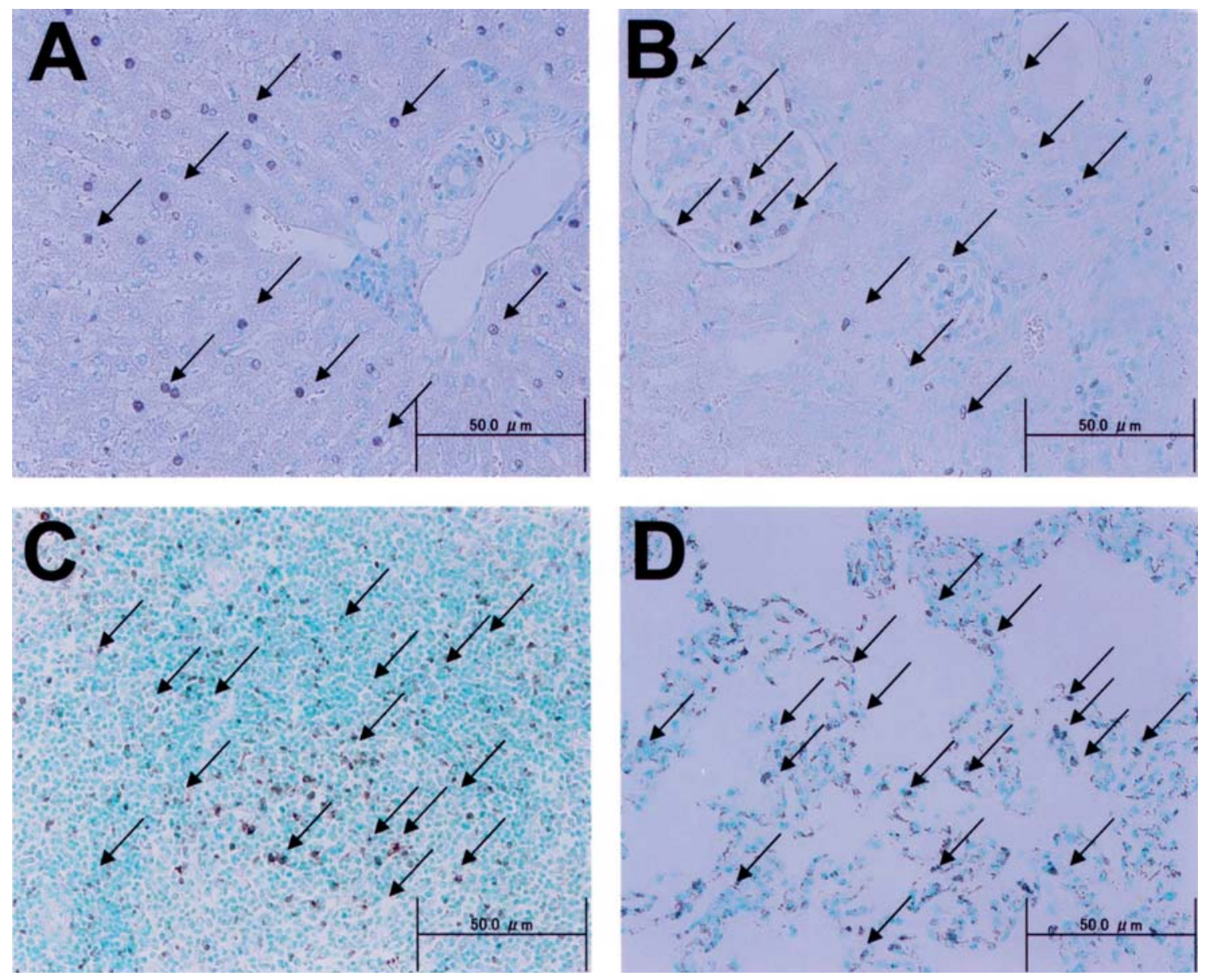

Figure 2. TUNEL signals in tumor-bearing rabbits. (A) Liver cells on day 50 after tumor implantation with an apoptotic index of $14.2 \pm 1.8 \%$ (arrows). (B) Kidney cells on day 50 with an apoptotic index of $34.4 \pm 2.0 \%$ (arrows). (C) Spleen cells on day 50 with an apoptotic index of $24.8 \pm 3.8 \%$ (arrows). (D) Lung cells on day 50 with an apoptotic index of $66.7 \pm 6.0 \%$ (arrows).

Differences were considered statistically significant when the $\mathrm{P}$-value was $<0.05$. All data were expressed as mean $\pm \mathrm{SD}$.

\section{Results}

Changes in total body weight and LBM. The total body weights of the animals were measured every 10 days after tumor implantation and expressed as ratios against the baseline values for comparisons between the two groups. At 10 days after tumor implantation, the total body weight of the rabbits implanted with VX2 carcinoma cells had decreased significantly to a ratio of $0.89 \pm 0.01$ (Fig. 1A).

The LBMs of the animals were also measured every 10 days and expressed as ratios against the baseline values. The LBM increased continuously in the control group to ratios of $1.02 \pm 0.02$ on day 10 and $1.05 \pm 0.02$ on day 40 , while that in the tumor-bearing group decreased significantly compared to the control group to $0.91 \pm 0.02$ on day 10 and $0.69 \pm 0.18$ on day 40 (Fig. 1B).

AI. Apoptosis in each organ was examined using the TUNEL method (Fig. 2). In the liver, the AI values in the tumorbearing group were $0.7 \pm 0.3,3.6 \pm 0.6,8.2 \pm 1.1,14.2 \pm 1.8$ and $4.0 \pm 0.8$ on days $20,30,40,50$ and 60 , respectively. The AI in the tumor-bearing group reached its maximum value on day 50 and decreased thereafter. The AI values in the tumor- bearing group were significantly $(\mathrm{P}<0.05)$ higher than those in the control group on days 30, 40, 50 and 60 (Fig. 3A).

In the kidney, the AI values in the tumor-bearing group were $9.2 \pm 1.7,23.3 \pm 3.8,22.4 \pm 2.5,34.4 \pm 2.0$ and $16.2 \pm 2.0$ on days $20,30,40,50$ and 60 , respectively. The AI in the tumorbearing group gradually increased until day 50 and then decreased on day 60. The AI values in the tumor-bearing group were significantly $(\mathrm{P}<0.05)$ higher than those in the control group on days 30, 40, 50 and 60 (Fig. 3B).

In the spleen, the AI values in the tumor-bearing group were $7.7 \pm 0.6,6.7 \pm 0.5,15.8 \pm 0.7,24.8 \pm 3.8$ and $11.8 \pm 1.6$ on days $20,30,40,50$ and 60 , respectively. The AI reached its maximum value on day 50 and decreased thereafter. The AI values in the tumor-bearing group were significantly $(\mathrm{P}<0.05)$ higher than those in the control group on days 30, 40, 50 and 60 (Fig. 3C).

In the lung, the AI values in the tumor-bearing group were $4.7 \pm 0.8,11.4 \pm 1.1,30.7 \pm 3.6,66.7 \pm 6.0$ and $17.8 \pm 2.0$ on days $20,30,40,50$ and 60 , respectively. The AI reached its maximum value on day 50 and decreased thereafter. The AI values in the tumor-bearing group were significantly $(\mathrm{P}<0.05)$ higher than those in the control group on days $30,40,50$ and 60 (Fig. 3D).

In the heart, no apoptotic cells were detected by the TUNEL method in both the tumor-bearing and the control groups (data not shown). 
A

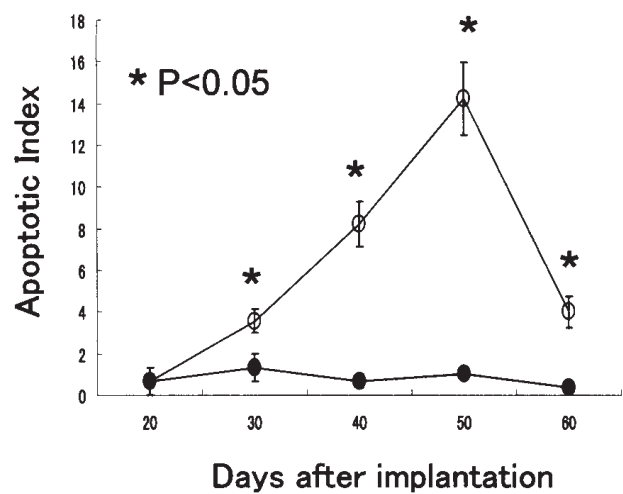

C

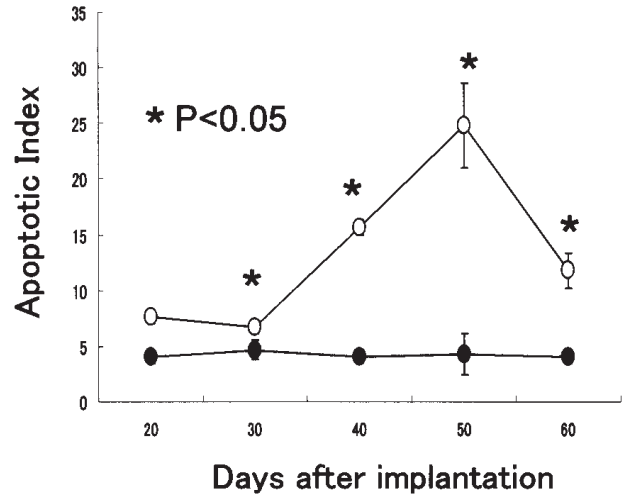

B

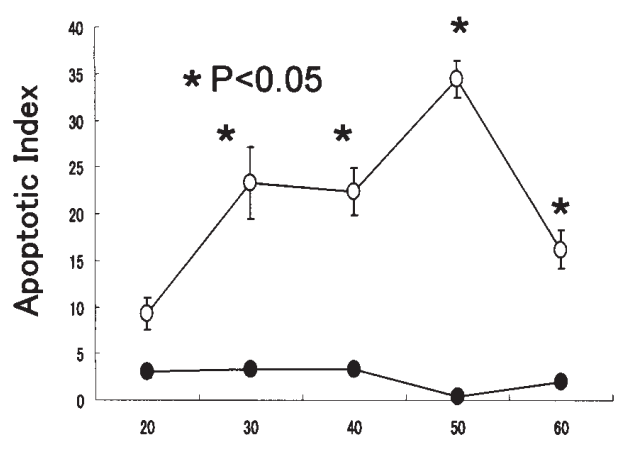

Days after implantation

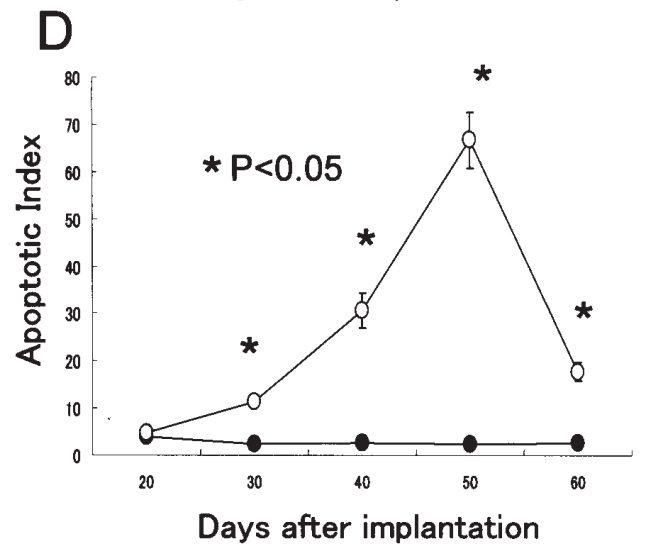

Figure 3. Changes in the apoptotic index values in the liver (A), kidney (B), spleen (C) and lung (D) of the tumor-bearing group (open circles) and the control group (closed circles). The apoptotic index was calculated based on the proportion of TUNEL-positive cells detected using a light microscope and a x200 magnification lens. Bars represent the SD. ${ }^{*} \mathrm{P}<0.05$ vs. the control group (Student's t-test).

A

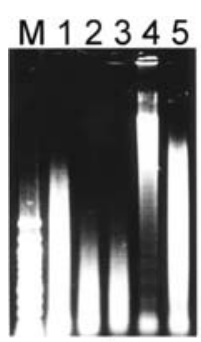

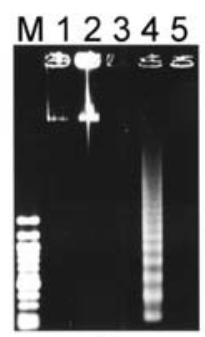

B

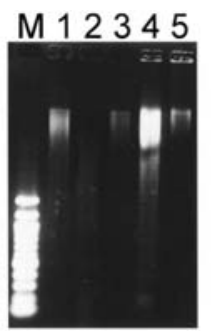

C

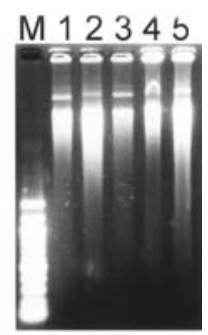

D
Figure 4. DNA fragmentation assays for the liver (A), kidney (B), spleen (C) and lung (D) of the tumor-bearing group. Lane M, DNA ladder marker. Lane 1, day 20 after tumor implantation. Lane 2, day 30 after tumor implantation. Lane 3, day 40 after tumor implantation. Lane 4, day 50 after tumor implantation and lane 5, day 60 after tumor implantation.

DNA laddering patterns. In the liver, kidney, spleen and lung, DNA laddering patterns characteristic of DNA fragmentation were visible on day 50 in the tumor-bearing group, but not detected on the other days examined. Such laddering patterns were not observed in the control group (Fig. 4).

In the heart, DNA laddering patterns were not visible in either the tumor-bearing or the control group (data not shown).

Expression levels of Bax, Bcl-2 and Bcl- $x_{L}$ proteins. The immunostaining signals specific for $B a x$ in each tissue are shown in Fig. 5. Bcl-2 and Bcl- $\mathrm{x}_{\mathrm{L}}$ immunoreactivities were either not detected at all or only weakly observed in the two groups. No particular expression trends for $\mathrm{Bcl}-2$ and $\mathrm{Bcl}-\mathrm{x}_{\mathrm{L}}$ were detected (data not shown). On the other hand, there were trends for Bax expression.

In the liver, Bax was expressed to its maximum level on day 50 after tumor implantation. The Bax expression levels were significantly $(\mathrm{P}<0.05)$ higher in the tumor-bearing than in the control group on days 40, 50 and 60 (Fig. 6A).

In the kidney, Bax expression increased until day 50. The Bax expression levels were significantly $(\mathrm{P}<0.05)$ higher in the tumor-bearing than in the control group on days 40,50 and 60 (Fig. 6B).

In the spleen, Bax expression increased slowly until day 60 and was significantly $(\mathrm{P}<0.05)$ higher in the tumor-bearing group than in the control group on day 60 (Fig. 6C).

In the lung, Bax expression peaked on day 50. The Bax expression levels were significantly $(\mathrm{P}<0.05)$ higher in the tumor-bearing than in the control group on days 50 and 60 (Fig. 6D).

\section{Discussion}

Cancer cachexia is accompanied by progressive body weight loss, anorexia, anemia and immunodeficiency (1). There have been many studies on the mechanism of cancer progression, especially on the cause of cachexia and three hypotheses have been proposed to explain the origin of cancer cachexia to date (2). The first is the metabolic competition hypothesis, which states that neoplastic cells function as nitrogen traps by 

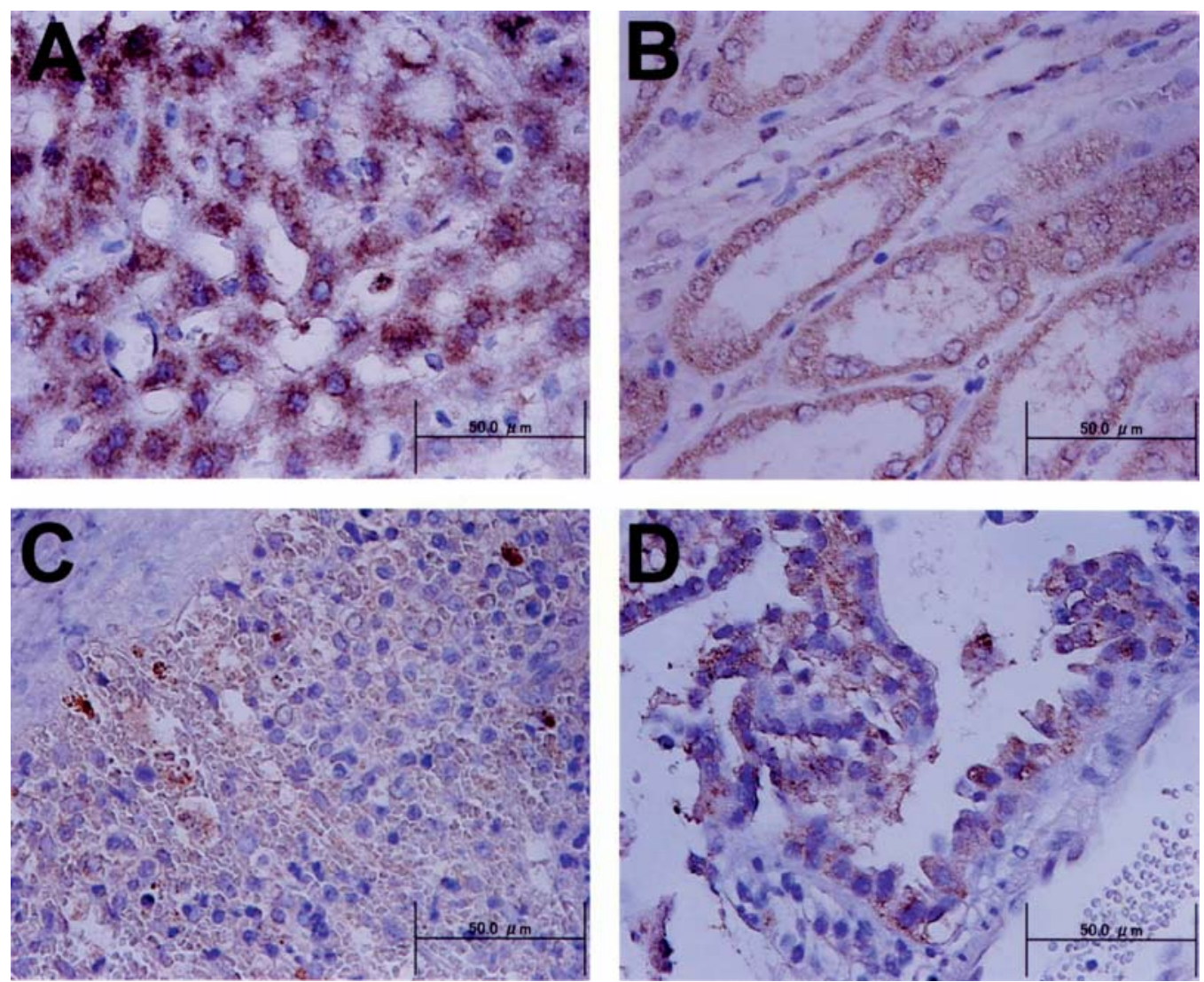

Figure 5. Immunohistochemical staining for Bax in tumor-bearing rabbits. (A) The liver on day 20 after tumor implantation. (B) The kidney on day 50 after tumor implantation. (C) The spleen on day 60 after tumor implantation. (D) The lung on day 50 after tumor implantation.
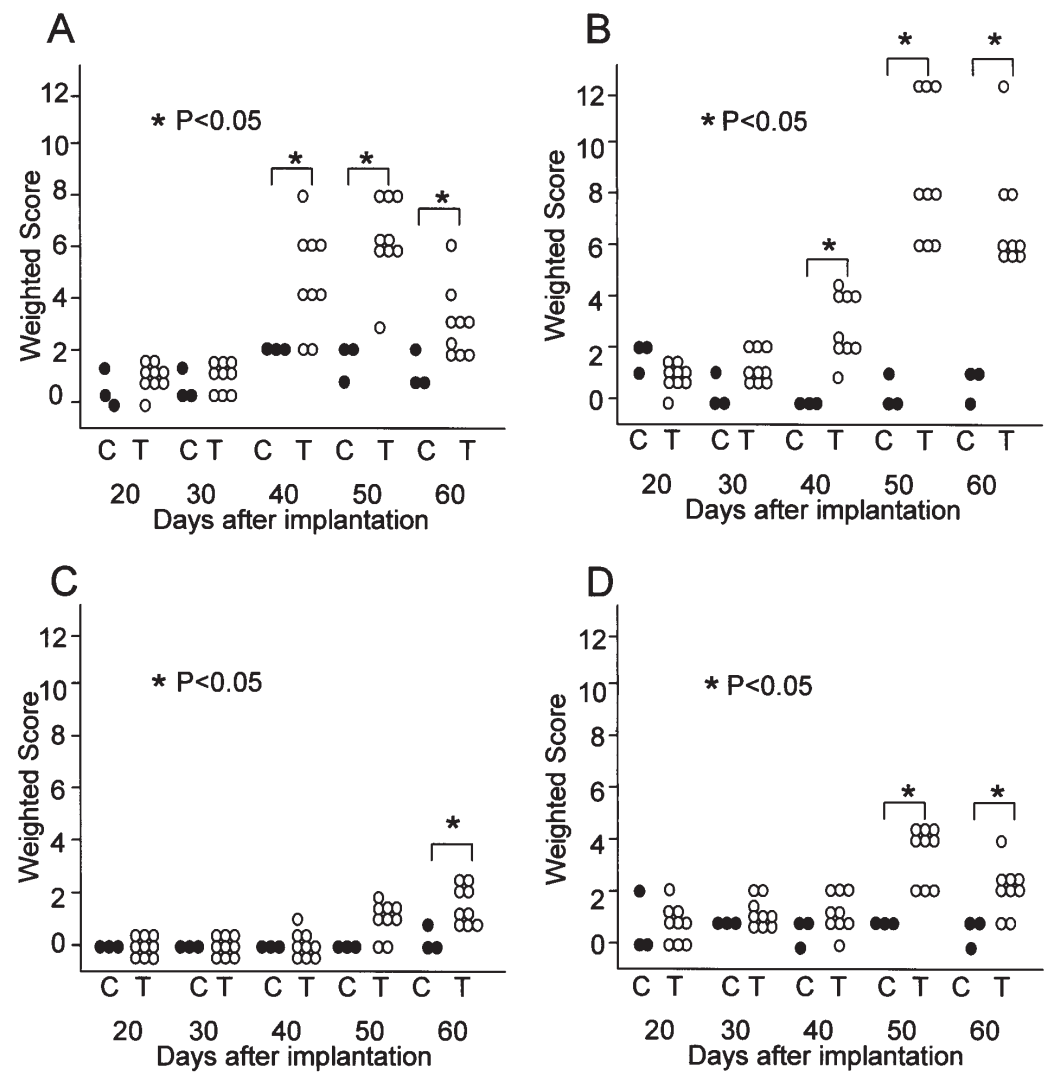

Figure 6. Weighted scores for Bax expression in the control group (C, closed circles) and the tumor-bearing group (T, open circles) in the liver (A), kidney (B), spleen (C) and lung (D). ${ }^{*} \mathrm{P}<0.05$ (Mann-Whitney U test). 
competing with host tissues for amino acids. The second is the malnutrition hypothesis, which attributes cachexia to profound protein loss after hypophagia or malabsorption. The third is the circulating humoral factor hypothesis, in which many biological substances have been proposed as candidate humoral factors involved in the development of cancer cachexia, starting with toxohormone in the 1940s (12) and later including tumor necrosis factor- $\alpha$, interleukin (IL)- $1 \alpha$, IL- $\beta$, IL-6, interferon- $\gamma$, leukemia inhibitory factor and LMF (13-18). We isolated and purified an anemia-inducing substance from the plasma of advanced cancer patients in 1987 and found that it induced immunodeficiency as well as anemia (19-21).

We studied cancer cachexia by using VX2 tumor-bearing rabbits, and found that body weight loss, anemia and immunodeficiency became marked at 30 to 40 days after implantation (22). In previous experiments using rats and mice, weight loss has mainly been examined at the stage when cachexia is obvious (23). However, we developed an original system for measuring LBM in rabbits and used it to chart the time course of body weight and LBM changes beginning with the early stage after implantation. The results showed that LBM and body fat began to decrease in the early stage after implantation, when the pathological manifestations of cachexia were not yet marked. We have also reported that apoptosis of normal skeletal muscle occurred in the early stage of tumor bearing (24) and that the expression of Bax increased in tumor-bearing rabbits and coincided with the occurrence of apoptosis (6). These observations strongly suggest that Bax is related to apoptosis in skeletal muscle in the early stage of tumor-bearing.

Apoptosis, also known as programmed cell death, is part of the normal processes of development and differentiation in multicellular organisms and also plays important roles in the death of normal cells and tumor cells (25-27). The Bcl-2 family members are highly involved in the control of apoptosis and $\mathrm{Bcl}-2$ protein is present in the mitochondrial outer membrane and nuclear membrane (28). Overexpression of Bcl-2 suppresses apoptosis (4), while one of its homologues, Bax, promotes apoptosis. It is claimed that Bcl-2 and Bax form homodimers and heterodimers and that the ratio between them controls apoptosis $(4,5)$. This apoptosis pathway via Bcl-2 family members has been noted in many other diseases.

In the present study, overexpression of Bax and normal organ cell apoptosis were detected in the liver, kidney, spleen and lung in the late stage of tumor bearing. In the heart, overexpression of Bax and normal cell apoptosis were not detected in either the tumor-bearing group or the control group. These observations suggest the possibility that apoptosis associated with Bax causes multiple organ failure in cancer cachexia. Apoptosis has been repeatedly demonstrated in established heart failure, both in humans and in animal models (29-31). In cachexia, heart failure progresses slowly and only becomes obvious just before death. Furthermore, the mechanism of heart failure in cancer cachexia may differ from those in ischemic change, hypertension, myopathy and so on. This could explain why apoptosis was not observed in the heart in the present study. Under tumor-bearing conditions, apoptotic cells are detected in normal organs other than the heart. This suggests not only that apoptosis causes body weight loss but also that apoptosis causes multiple organ failure in cancer cachexia. The results of the present study indicate that apoptosis in normal organs of cancer-bearing individuals may be controlled by Bax, an apoptosis-related protein and suggest that interrupting apoptosis may help attenuate the progression of cancer cachexia, including body weight loss and multiple organ failure.

\section{Acknowledgements}

This study was supported in part by grants from the Ministry of Education, Culture, Sports, Science and Technology of the Japanese Government.

\section{References}

1. Tisdale MJ: Cancer cachexia. Br J Cancer 63: 337-342, 1991.

2. Toomey D, Redmond HP and Bouchler-Hayes D: Mechanisms mediating cancer cachexia. Cancer 76: 2418-2426, 1995.

3. Tsujimoto $\mathrm{Y}$ and Crose CM: Analysis of the structure, transcripts, and protein products of bcl-2, the gene involved in human follicular lymphoma. Proc Natl Acad Sci USA 83: 5214-5218, 1986.

4. Reed JC: Bcl-2 and the regulation of programmed cell death. J Cell Biol 124: 1-6, 1994.

5. Oltvai ZN, Milliman CL and Korsmeyer SJ: Bcl-2 heterodimerizes in vivo with a conserved homolog, Bax, that accelerates programmed cell death. Cell 74: 609-619, 1993.

6. Yosida H, Ishiko O, Sumi T, Honda K, Hirai K and Ogita S: Expression of apoptosis regulatory proteins in the skeletal muscle of tumor-bearing rabbits. Jpn J Cancer Res 92: 631-637, 2001.

7. Ishiko O, Sumi T, Yoshida H, Hyun Y and Ogita S: Comparison of expression of apoptosis regulatory proteins in the adipose tissue of tumor-bearing and diet-restricted rabbits. Int J Mol Med 8: 543-547, 2001.

8. Kidd JG and Rous P: A transplantation rabbit carcinoma originating in a virus-induced papilloma and containing the virus in masked or altered from. J Exp Med 71: 813-838, 1940.

9. Yasui T, Ishiko O, Ogita S, et al: Body composition analysis of cachectic rabbits by total body electrical conductivity. Nutr Cancer 32: 201-205, 1998.

10. Gavrieli Y, Sherman Y and Ben-Sasson SA: Identification of programmed cell death in situ via specific labeling of nuclear DNA fragmentation. J Cell Biol 119: 493-501, 1992.

11. Sinicrope FA, Ruan SB, Cleary KR, Stephens LC, Lee JJ and Levin B: bcl-2 and p53 oncoprotein expression during colorectal tumorigenesis. Cancer Res 55: 237-241, 1995.

12. Nakahara W and Fukuoka F: Toxohormone, a characteristic toxic substance produced by cancer tissue. Jpn J Cancer Res 40: 45-69, 1949.

13. Dinarello C and Wolff SM: The role of interleukin-1 in disease. N Engl J Med 328: 106-113, 1993.

14. Strassmann G, Fong M, Kenney JS and Jacob CO: Evidence for the involvement of interleukin 6 in experimental cancer cachexia. J Clin Invest 89: 1681-1684, 1992.

15. Langstein HN, Doherty GM, Franker DL, Buresh CM and Norton JA: The roles of $\gamma$-interferon and tumor necrosis factor in an experimental rat model of cancer cachexia. Cancer Res 51: 2302-2306, 1991

16. Kawakami $M$ and Cerami A: Studies of endotoxin-induced decrease in lipoprotein lipase activity. J Exp Med 154: 631-639, 1981.

17. Moroi M, Yamaguchi K and Abe K: Purification of a lipoprotein lipase-inhibiting protein produced by a melanoma cell line associated with cancer cachexia. Biochem Biophys Res Commun 160: 1085-1092, 1989.

18. Todorov P, Cariuk P, McDevitt T, Coles B, Fearon K and Tisdale MJ: Characterization of a cancer cachectic factor. Nature 379: 739-742, 1996.

19. Ishiko O, Sugawa T, Tatsuta I, Shimura K, Naka K, Deguchi M and Umesaki N: Anemia-inducing substance (AIS) in advanced cancer: inhibitory effect of AIS on the function of erythrocytes and immunocompetent cells. Jpn J Cancer Res 78: 596-606, 1987. 
20. Ishiko O, Deguchi M, Tatsuta I, et al: Removal of immunosuppressive substance in cancer patients' serum. Jpn J Cancer Res 81: 564-566, 1990

21. Honda K, Ishiko O, Tatsuta I, et al: Anemia-inducing substance from plasma of patients with advanced malignant neoplasms. Cancer Res 55: 3623-3628, 1995.

22. Ishiko O, Hirai K, Nishimura S, et al: Elimination of anemiainducing substance by cyclic plasma perfusion of tumor-bearing rabbits. Clin Cancer Res 5: 2660-2665, 1999.

23. Obeid OA and Emercy PW: Lipid metabolism in cachectic tumor-bearing rats at different stages of tumor growth. Nutr Cancer 19: 87-98, 1993.

24. Ishiko O, Sumi T, Hirai K, Honda K, Nakata S, Yoshida H and Ogita S: Apoptosis of muscle cells causes weight loss prior to impairment of DNA synthesis in tumor-bearing rabbits. Jpn J Cancer Res 92: 30-35, 2001.

25. Kerr JFR, Wyllie AH and Currie AR: Apoptosis: a basic biological phenomenon with wide-ranging implications in tissue kinetics. Br J Cancer 26: 239-257, 1972.
26. Williams GT: Programmed cell death: apoptosis and oncogenesis. Cell 65: 1097-1098, 1991.

27. Raff MC: Social controls on cell survival and cell death. Nature 356: 397-400, 1992.

28. Krajewski S, Tanaka S, Takayama S, Schibler MJ, Fenton W and Reed JC: Investigation of the subcellular distribution of the bcl-2 oncoprotein: residence in the nuclear envelope, endoplasmic reticulum, and outer mitochondrial membranes. Cancer Res 53: 4701-4714, 1993.

29. Narula J, Haider N, Virmani R, et al: Apoptosis in myocytes in end-stage heart failure. N Engl J Med 335: 1182-1189, 1996.

30. Olivetti G, Abbi R, Quaini F, et al: Apoptosis in the failing human heart. N Engl J Med 336: 1131-1141, 1997.

31. Garg S, Narula J and Chandrashekhar Y: Apoptosis and heart failure: clinical relevance and therapeutic target. J Mol Cell Cardiol 38: 73-79, 2005. 